\title{
Colon Cancer by AJCC v8 Stage
}

National Cancer Institute

\section{Source}

National Cancer Institute. Colon Cancer by A/CC v8 Stage. NCI Thesaurus. Code C134251.

A term that refers to the staging of colon cancer according to the American Joint Committee on Cancer, 8th edition. This staging system applies to adenocarcinomas, high-grade neuroendocrine carcinomas, and squamous cell carcinomas of the colon. (from AJCC 8th Ed.) 